\title{
ARTICLE
}

\section{Mindfulness, mental health and emotion regulation among workers}

\author{
Simon Grégoire • Lise Lachance · Geneviève Taylor
}

\begin{abstract}
Few studies have been conducted to examine the relationship between mindfulness training and emotion regulation at work. This study reports results from a semi-randomized controlled trial of a brief Mindfulness-Based Intervention (MBI) (Grégoire \& Lachance, 2015) delivered in audio format. A pretest-posttest switching-replication design was used to assess changes in mindfulness, mental health (psychological wellbeing, psychological distress, stress and burnout) and emotion regulation (emotion awareness and impulse control) among forty-one ( $N=$ 41) employees working in a call center. Data was collected using self-report questionnaires at baseline (t1), week 6 (t2), week 11 (t3) and week 25 (t4) in order to have a follow-up measure. Both the analysis of variance and the prediction analysis showed that the intervention helped increased mindfulness and psychological wellbeing, but also reduced psychological distress, stress and burnout among employees. Overall, the intervention helped employees refrain from impulsive or reactive behavior when experiencing negative emotions but had no significant effect on their emotional awareness. Finally, there was a trend toward emotion regulation mediating the effects of the intervention on psychological distress.
\end{abstract}

Keywords: mindfulness, mental health, emotion regulation, intervention, workplace

\section{Introduction}

Call centers can be stressful work environments (De Cia et al., 2012). Research shows that there is significantly more stress in call centers than in other work environments $(15 \%$ vs $11 \%$ respectively; The Shepell.fgi Research Group, 2008) and that many call center agents experience either mild (39.4\%) or severe (8.3\%) psychological distress symptoms (Charbotel et al., 2009). Call center agents also face great emotional demands (Grebner et al., 2003). According to a survey conducted by The Shepell.fgi Research Group (2010), over 40\% of call center agents deal with angry clients every day. They are often victims of verbal aggression from clients or find themselves in a state of emotional dissonance, for instance, they have to maintain a professional, helpful and caring attitude while feeling angry, sad or diminished. Such emotional labor may in part explain why there are significantly more emotional problems, such as anxiety and depression, in call centers than in other workplaces (19\% vs 15\%; The Shepell.fgi Research Group). These statistics indicate that there is a need for interventions that could help promote mental health and the use of effective emotion regulation strategies among call center employees.

The aim of the present study was to assess the efficacy of a Mindfulness-Based Intervention (MBI) recently developed by Grégoire and Lachance (2015). The authors have shown that this intervention helps to reduce psychological distress among call center employees. This study extends their work in four important ways. First, the efficacy of their intervention was assessed using both positive (psychological wellbeing) and negative (psychological distress, stress and 
burnout) mental health indicators. According to a growing number of researchers, mental health measures should not only include manifestations of psychological distress but manifestations of psychological wellbeing as well (Massé et al., 1998). Secondly, this study explores the effect of Grégoire and Lachance's (2015) intervention on two critical emotion regulation abilities among call center employees (i.e., emotion awareness and impulse control). It has been shown that the extent to which these employees are aware of their own emotions (as well as those of their clients) and refrain from impulsive or reactive behavior when experiencing negative emotions positively affects both their performance (Nel \& De Villiers, 2004; Shamsuddin \& Rahman, 2014) and their job satisfaction (Çekmecelioğlu, Günsel, \& Ulutaş, 2012). In this study, a mediating framework was tested in which the effects of the intervention on call center employees' mental health would depend on how they regulated their emotions. Although promising studies have been conducted recently on the role of mindfulness for emotion regulation at work (Hülsheger, Alberts, Feinholdt, \& Lang, 2013), research in this field is still scarce (Glomb, Duffy, Bono, \& Yang, 2011). Third, the effects of the intervention developed by Grégoire and Lachance (2015) were assessed using a three months follow-up period. As noted by Virgili (2013), the longer-term impact of MBIs in the workplace are rarely assessed. Fourth, compared to Grégoire and Lachance's (2015) original study, the current research took into account employees' compliance with the intervention. According to Goyal et al. (2014), it is important to control for this variable since participants' level of engagement in MBIs may moderate their effectiveness. The background behind these goals is elaborated next.

\section{Mindfulness and mental health}

Lately, various MBI's (Cullen, 2011) have been integrated in the workplace as part of mental health prevention initiatives (Escuriex \& Labbé, 2011; Irving, Dobkin, \& Park, 2009; Virgili, 2013). Mindfulness is usually defined as the act of "paying attention in a particular way: on purpose, in the present moment, and nonjudgmentally" (Kabat-Zinn, 1994, p. 4). MBIs are structured group interventions aimed at helping people cultivate mindfulness; they integrate ancient Buddhist as well as modern clinical practices (Keng, Smoski, \& Robins, 2011). These interventions rely on various meditation techniques, either as a stand-alone intervention or combined with existing psychological interventions, such as cognitive-behavioral therapy (Chambers, Gullone, \& Allen, 2009). In MBIs, participants are trained to consciously keep their attention and awareness focused on whatever is present (breath, thoughts, emotions, etc.), without fixating on any particular part of that experience or engaging in any secondary processing. They are encouraged to observe their mental phenomena as they manifest while noting any tendency to evaluate or appraise, and to consciously avoid engaging in these processes (Chambers et al., 2009). The goal is to develop the ability to calmly step back from thoughts and feelings during stressful situations, rather than engage in anxious worry or other negative thinking patterns that might otherwise escalate into a cycle of stress reactivity (Bishop, 2002).

Originally developed in clinical settings, MBIs such as the Mindfulness-Based Stress Reduction program (MBSR; Kabat-Zinn, 1990), Acceptance and Commitment Therapy ${ }^{1}$ (ACT; Hayes, Strosahl, \& Wilson, 1999) and Mindfulness-Based Cognitive Therapy (MBCT; Segal, Williams, \& Teasdale, 2002) have been implemented lately in workplaces such as schools (Flook, Goldberg, Pinger, Bonus, \& Davidson, 2013; Roeser et al., 2013), hospitals (Bazarko, Cate, Azocar, \& Kreitzer, 2013; Mackenzie, Poulin, \& Seidman-Carlson, 2006), telecommunications companies (Bond \& Bunce, 2000) and call centers (Walach et al., 2007). Adaptations of these MBIs have also

\footnotetext{
${ }^{1}$ The term "training" rather than "therapy" is usually used in work settings.
} 
been proposed where the form, content and overall duration of training were slightly adjusted in order to fit specific work environments. For example, brief (Klatt, Buckworth, \& Malarkey, 2009; Mackenzie et al., 2006), on-line (Malarkey, Jarjoura, \& Klatt, 2013) and audio (Grégoire \& Lachance, 2015) versions of MBIs have been recently introduced in organizations.

A growing amount of evidence suggests that MBIs implemented in the workplace help reduce stress (Bazarko et al., 2013; Geary \& Rosenthal, 2011; Gold et al., 2010; Klatt et al., 2009; Pipe et al., 2009; Roeser et al., 2013; Roeser, Skinner, Beers, \& Jennings, 2012; Shapiro, Astin, Bishop, \& Cordova, 2005; Walach et al., 2007; Wolever et al., 2012), anxiety (Gold et al., 2010; Ruths et al., 2013), depression (Bond \& Bunce, 2000; Gold et al., 2010; Hayes et al., 2004), burnout (Bazarko et al., 2013; Cohen-Katz, 2004; Flook et al., 2013; Galantino, Baime, Maguire, Szapary, \& Farrar, 2005; Goodman \& Schorling, 2012; Krasner et al., 2009; Mackenzie et al., 2006; Martín, Rodríguez, Pujol-Ribera, Berenguera, \& Moix Queraltó, 2013; Roeser et al., 2013; Shapiro et al., 2005), negative affect (Galantino et al., 2005), and psychological distress (Franco, Mañas, Cangas, Moreno, \& Gallego, 2010; Shapiro et al., 2005). In a recent meta-analysis including 19 controlled and uncontrolled intervention studies, Virgili (2013) showed that MBIs had a robust mediumlarge effect on employees' psychological distress. The overall within-group (pre-post) effect was Hedges's $g=.68$ (95\% CI [.58, .78]), while the posttreatment between-group effect size for MBI compared with an inactive control was Hedges's $g=.68$ (95\% CI $[.48, .88])$. Correlational studies conducted in organizations corroborate these results and indicate that mindfulness is negatively related to the number of sick-leave days and medical treatment utilization (Dahl, Wilson, \& Nilsson, 2004), burnout (Abdool Karrim Ismail, Coetzee, Du Toit, Rudolph, \& Joubert, 2013; Reb, Narayanan, \& Ho, 2013), negative affect, sleep related impairment, daily physical symptoms and perceived stress (Abenavoli, Jennings, Greenberg, Harris, \& Katz, 2013).

Taken together, these studies suggest that MBIs represents a valuable way to reduce negative mental health outcomes such as psychological distress. However, their impact on positive outcomes remains unclear despite the fact that mental health and, conversely, mental ill-health, are usually conceptualized as a spectrum ranging from 'positive mental wellbeing' to mental illhealth and clinical problems (Hassard, Cox, Murawski, \& DeMeyer, 2011). Goyal et al., (2014) noted that few mindfulness studies include wellbeing indicators. Based on the randomized controlled trials they reviewed to test the efficacy of MBIs within clinical populations, they concluded that although positive outcomes are a key focus of meditative practices, most trials did not include positive outcomes such as wellbeing, either as primary or secondary outcomes. Moreover, it remains unclear whether or not the effect of MBIs last over time. In their metaanalysis, Virgili (2013) noted that only 6 studies (out of 19) included follow-up and that the length of these follow-ups was rather short (8.3 weeks on average). He concluded that at this point, we still do not know much about the long-term effectiveness of MBIs. What also remains unclear are the variables that moderate or mediate the relationship between mindfulness training and mental health (Baer, 2010). Various authors have pointed out that participants' level of engagement or compliance during MBIs may influence the impact of this type of intervention (Goyal et al., 2014). Others argue that the effect of these interventions on mental health depends, at least in part, on its effects on employees' emotion regulation (Glomb et al., 2011; Hülsheger et al., 2013).

\section{Mindfulness and emotion regulation}

Emotion regulation can be defined as the ability to regulate one's own emotions and emotional responses (Gross, 1998). It is usually assumed that adaptive emotion regulation promotes mental health and adaptive functioning, while emotional dysregulation is part of many disorders such as depression and anxiety (Chambers et al., 2009). According to a growing number of authors, 
mindfulness training may promote emotion regulation. For example, Shapiro, Carlson, Astin and Freedman (2006) argue that through a process called reperceiving, people gradually develop, throughout their mindfulness training, the ability to observe their thoughts and feelings from a distance and see them as temporary events in the mind that do not necessitate particular responses, rather than as reflections of the self that are necessarily true or important. By learning to intentionally focus nonjudgmental attention on the contents of their mind, they begin to strengthen what Hayes, Strosahl, and Wilson (2011) call their "observing self". Shapiro et al. (2006) argue that this particular shift in perspective brings clarity, objectivity, and equanimity, which in turn, promotes better emotion regulation. In their model, mindfulness training is conceptualized as a response-focused type of regulation that focuses on changing a person's relationship to his or her emotions rather than the nature of the emotions themselves (Chambers et al., 2009). Others maintain that mindfulness training promotes emotion regulation by improving self-control or executive control (Friese, Messner, \& Schaffner, 2012; Muraven \& Baumeister, 2000). For instance, Teper, Segal and Inzlicht (2013) argue that when mindful, people are more aware of their interoceptive signals, which give them precious insights about their body's affective responses to events. When such visceral sensations signal conflict between current behavior and a goal state, they are able to recognize it and mobilize self-regulatory resources, thereby avoiding the rumination that often ensues. For instance, if someone is able to focus on the bodily sensations of anger (e.g., rapid breathing), he or she can quickly recognize that control is needed. Teper et al. (2013) also argue that when mindful, people are in a better position to accept and respond efficiently to affective signals that are vital in initiating adaptive behavior (i.e., regulation) instead of elaborating on them or suppressing them. In other words, the authors maintained that "people who are able to feel and accept the initial pang of affect will also be able to quickly mobilize the necessary regulatory resources, minimizing the negative consequences associated with full-blown emotional reactions" (Teper et al., 2013, p. 452).

The Shapiro et al. (2006) and Teper et al. (2013) models both suggest that mindfulness may be especially helpful for developing emotional awareness (Erisman \& Roemer, 2010) and impulse control (Feldman, Greeson, \& Senville, 2010). Emotional awareness is defined as the extent to which people are aware of emotions in both themselves and others (Ciarrochi, Caputi, \& Mayer, 2003) while impulse control is the ability to refrain from impulsive or reactive behavior when experiencing negative emotions (Gratz \& Roemer, 2004). These are critical abilities for call center agents as they have to interact with clients and customers on a regular basis and face many emotional demands (Grebner et al., 2003; Shamsuddin \& Rahman, 2014). In fact, these employees sometimes get insulted or have to deal with clients' impatience, anger or frustration, which elicits all kind of emotions in them. By learning to develop a more mindful stance and reperceive their emotional experiences (Shapiro et al., 2006), call center employees may come to manage even complicated and confusing emotions with more clarity while interacting with their clients (Erisman \& Roemer, 2010). As suggested by Teper et al. (2013), they may recognize subtle changes in their affective states more easily and notice specific information related to their emotions, such as their origin or their consequences (Hill \& Updegraff, 2012). They may also learn to respond to their emotions with greater self-control, flexibility and equanimity instead of reacting to them in an impulsive, automatic or rigid way (Masicampo \& Baumeister, 2007; Shapiro et al., 2006).

These ideas have recently received empirical support outside organizational settings. In an experience-sampling study, for instance, Hill and Updegraff (2012) asked undergraduate students to report their current emotional experiences six times per day throughout the course of one week on a Palm Pilot device. They found that self-reported mindfulness was positively 
related to emotional awareness (as measured by the ability to describe subtle differences between discrete emotions) and negatively related to emotion reactivity (as measured by less emotion liability for both negative and positive emotions). In a series of correlational studies, Fetterman, Robinson, Ode and Gordon (2010) found self-reported mindfulness to be positively related to self-control and negatively related to impulsivity, while Baer, Smith and Allen (2004) found that it was associated with attention to feelings and with clarity of feelings. In a laboratory study, Feldman et al. (2010) asked undergraduate students to go through a short (15 minutes) audio mindfulness meditation training. The authors found the training to be helpful at reducing reactivity to repetitive thoughts. In other words, participants were more likely to experience ruminative thoughts and emotions without becoming emotionally distressed by them.

Considering that emotion regulation is a critical ingredient of mental health (Chambers et al., 2009) and that preliminary evidence suggests that mindfulness training helps promote emotional awareness and impulse control (Baer et al., 2004; Feldman et al., 2010; Fetterman et al., 2010), we argue that the effects of the intervention developed by Grégoire and Lachance (2015) on employee's mental health should be mediated by their impact on these two emotional strategies. Throughout their mindfulness training, employees may gain more emotional awareness and control, which in turn, may positively affect their mental health. This mediation framework is in part supported by two studies recently conducted by Hülsheger et al. (2013). The authors conducted a diary as well as an experimental field study in order to explore the relationship between mindfulness and surface acting, a common emotion regulation strategy among employees working in emotionally demanding jobs (e.g., employees interacting with aggressive or unpleasant clients). Surface acting aims at altering the outward emotional expression without changing the actual feeling. It involves suppressing negative and faking positive emotional expressions for jobs holding positive emotional display rules (Grandey, 2000). Although often encouraged and supported in organizations, this strategy undermines employees' well-being and increases their emotional exhaustion, partly because it is effortful and depletes mental resources (Hülsheger et al., 2013). In their studies, Hülsheger et al. (2013) found mindfulness to be helpful at reducing the use of surface acting among employees working in a broad range of service jobs, which, in turn, reduced their emotional exhaustion.

\section{Objectives and hypotheses of the study}

The aim of this study was to assess the effect of a MBI developed by Grégoire and Lachance (2015) on three outcomes: mindfulness, emotion regulation and mental health. The latter was operationalized with positive (i.e., psychological wellbeing) and negative (i.e., psychological distress, stress and burnout) indicators according to Goyal et al.'s (2014) recommendation. Psychological wellbeing is a state characterized by happiness, mental balance or social involvement, while psychological distress is defined as an emotional suffering characterized by symptoms such as irritability, depression, anxiety and self-depreciation (Massé et al., 1998). Stress refers to the emotional and physiological reactions experienced when a person confronts a situation in which the demands go beyond his or her coping resources (Lazarus \& Folkman, 1984). Burnout is a chronic stress reaction and can be defined as an affective state characterized by depletion of physical fatigue, emotional exhaustion, and cognitive weariness (Shirom, 1989). Based on past literature, the following hypotheses were formulated:

Hypothesis 1: Mindfulness will increase from pre to post-intervention;

Hypothesis 2: Mental health will increase from pre to post-intervention (psychological wellbeing will increase while psychological distress, stress and burnout will decrease); 
Hypothesis 3: Emotional awareness and impulse control will increase from pre to postintervention;

Hypothesis 4: The effects of the intervention on mental health will be mediated by change in both emotional awareness and impulse control.

\section{Method}

\subsection{Participants}

The intervention described below was presented to one hundred and twenty five $(n=125)$ employees working in the call center of a large not-for-profit organization in Canada offering automotive, travel, residential and financial services and products. Seventy-one employees $(n=71)$ chose to take part in the intervention on a voluntary basis, with an overall response rate of $56.8 \%$, which is typical for studies in the organizational field (Baruch \& Holtom, 2008). Since thirty participants did not complete all four questionnaires included in this study, the analyses were conducted on a sample of forty-one employees $(n=41)$. Chi-square and independent sample $t$-tests revealed no significant gender and age differences or differences regarding the outcome variables under study between employees who completed the study and those who did not. Sample sizes at each time of assessment are presented in Table 1 below.

Table 1. Pretest-posttest control group design with switching-replication

\begin{tabular}{|c|c|c|c|c|c|c|c|c|c|c|c|c|}
\hline & $\begin{array}{c}\mathrm{t} 1 \\
n=71\end{array}$ & & & & & $\begin{array}{c}\mathbf{t} 2 \\
n=59\end{array}$ & & & & & $\begin{array}{c}\mathrm{t} 3 \\
n=45\end{array}$ & $\begin{array}{c}\mathrm{t} 4 \\
n=41\end{array}$ \\
\hline & W1 & W2 & W3 & W4 & W5 & W6 & W7 & W8 & W9 & W10 & W11 & W25 \\
\hline & & $\mathrm{X} 1$ & X2 & X3 & X4 & X5 & & & & & & \\
\hline Gr. 1 & O & & & & & ○ & & & & & 0 & ○ \\
\hline Gr. 2 & 0 & & & & & 0 & $\mathrm{X} 1$ & $X 2$ & X3 & $X 4$ & $\begin{array}{c}\mathrm{X} 5 \\
0\end{array}$ & 0 \\
\hline
\end{tabular}

Note. $\mathrm{t}=$ Times of measurement; $\mathrm{Gr}=$ Semi-randomized groups; $\mathrm{W}=$ Weeks; $\mathrm{X}=$ Interventions; $\mathrm{O}=$ Data collection

Over half of the employees who took part in this study were women (58.5\%). Ninety percent $(90 \%)$ of the participants were call center agents, while the others were managers. The mean age was 36.1 years, with an age range of 22 to 61 years. Employees received no monetary compensation or other kinds of incentives for taking part in this study.

\subsection{Description of the intervention}

The five-week intervention used in this study has been described in detail elsewhere (Grégoire \& Lachance, 2015). Every day, for five consecutive weeks, employees were guided through a 10minute audio meditation session in the morning, before beginning their work, and an additional 5 -minute audio session immediately after lunch. All guided meditation sessions were created and recorded by a Shambhala Buddhist nun with more than 15 years of experience in teaching mindfulness meditation. The sessions covered five different themes: attention to body sensations (week 1), attention to the breath (week 2), attention to sounds and silence (week 3), attention to emotions (week 4) and awakening confidence (week 5). Although this secular intervention is based on common processes usually used in MBIs (i.e., attention and awareness, acceptance and openness, decentering), it also has its own particularities. In regard to its form, this intervention could certainly be described as a low-dose (or brief) MBI as it relies on slightly more than six hours of training. In comparison, typical MBSR protocols range from twenty to thirty hours of 
training and participants are encouraged to practice meditation at home for 45 minutes per day, six days a week. This intervention can also be described as a self-help intervention, since it is mostly delivered in audio format and employees do not have much interaction with their instructor or other members of a group (see the procedure section below) (Cavanagh, Strauss, Forder, \& Jones, 2014). In terms of content, this intervention relies on basic meditation instructions and concrete tips on how to be more mindful of body sensations or emotions, for instance. The sessions were built so that the instructor would teach basic skills (usually during the morning session) and then encourage employees to practice these skills (typically in the afternoon session). It is important to emphasize that the aim of this intervention is to initiate employees to mindfulness meditation in a convenient and flexible way and help them integrate attention and awareness into their workdays. This intervention does not have the depth or the complexity of traditional MBIs such as MBSR or ACT and was not put forward to replace any of these interventions.

The guided meditation sessions were integrated into the employees' regular work schedule. They were uploaded in mp3 format on an internal server or on portable media players. Therefore, employees were able to listen to their meditation sessions either at their workstation with a headset or in a training room dedicated to the project with a portable media player. In both cases, precautions were taken to make sure the employees were undisturbed during the sessions. For example, when at their workstation, they were asked to turn off their computer screen or move their chair away from it and close their eyes while listening to the audio sessions. There were also given a please do not disturb sign, which they could hang on their office door or put on their desk when listening to a session. When in the training room, employees were encouraged to sit on a chair and face the wall to avoid any potential distractions. They were also asked to remain quiet and not to disturb their colleagues. Since call centers can be noisy, most employees (78\%) chose to listen to their guided meditations inside the training room.

\subsection{Research design}

The intervention was assessed using a pretest-posttest control group switching replication design (Trochim \& Donnelly, 2007), which means that during the first portion of the study, Group 1 acted as the intervention group while Group 2 acted as the control. During the second portion, the intervention was repeated and the roles were switched: Group 1 became the control group while Group 2 became the intervention group. For members of Group 1, the meditation sessions were made available at $\mathrm{t} 1$, while for Group 2, they were made available at $\mathrm{t} 2$ (see Table 1 above).

To randomly assign participants to either Group 1 or 2 and create groups of similar sizes, the random function in Excel was used to generate a number for each participant. The employees with odd numbers were then assigned to Group 1 while those with even numbers were assigned to Group 2. Among the seventy-one employees interested by the intervention, four were not able to take part in their allocated group as they had vacations or other requirements that were already scheduled. Therefore, groups could not be fully randomized and had to be slightly adjusted to accommodate these employees. Thirty-nine participants were assigned to Group 1 $(n=39)$ while thirty-six were assigned to Group $2(n=32)$. As previously mentioned, a total of forty-one employees $(n=41)$ completed the intervention and filled out all questionnaires. Of these, twenty-six employees were part of Group $1(n=26)$, and fifteen employees were part of Group $2(n=15)$. 


\subsection{Procedure}

The study lasted twenty-five weeks and was held from March to September 2013. First, an e-mail in which the intervention was briefly presented was sent to all employees working in the call center. The intervention was presented as an initiative to promote mental health in the workplace and reduce occupational stress. Those wanting to know more about this initiative were invited to take part in a one-hour information session held during regular work hours. Because it was impossible to meet all employees at once, six information sessions of about 10 employees were held. The goal of these sessions was to explain the aim and format of the intervention, but also to give the participants basic information on what mindfulness is, and why it is important to adopt a mindful stance at work. The sessions were held by the first author of this study, the Buddhist nun introduced earlier, and the managers responsible for the project. Employees interested in the intervention were invited to fill out a questionnaire immediately after these sessions (first assessment, $\mathrm{t} 1$ ). The other assessments were completed at week 6 (t2), week 11(t3) and week 25 (t4) (see Table 1 above). The groups were created after this information session.

An additional session was also set up at the beginning of week 5 for Group 1 and week 10 for Group 2 (see Table 1 above). This one-hour meeting was led by the Buddhist nun and was intended to provide the participants with additional training on how to be more attentive to their emotions at work, as a complement to the audio sessions. For instance, employees were encouraged to conceptualize their emotions as impermanent mental events and observe them come and go without trying to act upon them. The aim of this meeting was also to connect with employees and answer any questions they had regarding their mindfulness practice.

\subsection{Measures}

Demographic variables were assessed at $\mathrm{t} 1$. Employees were asked to report their age, gender and job title. The other variables were assessed at all four data-collection time points (t1, t2, t3 and $t 4)$.

Mindfulness was assessed using the Mindfulness Attention Awareness Scale (MAAS; Brown \& Ryan, 2003; Jermann et al., 2009). The MAAS uses 15 items where participants must indicate how frequently they experience various situations (e.g. "I find myself doing things without paying attention" using a scale a scale from one ("almost always") to six ("almost never"). Scoring of the MAAS involves calculating mean performance across the 15 items, with higher scores indicating greater mindfulness.

Mental health was assessed using four indicators. Respondents were asked to evaluate how often, over the last seven days, they had experienced various manifestations of wellbeing, distress, stress and burnout. Psychological wellbeing was assessed with the Psychological WellBeing Manifestations at Work Scale (Gilbert, Dagenais-Desmarais, \& Savoie, 2011). This scale contains 22 items and captures three factors: serenity (e.g. "I was able to face difficult situations in a positive way"), involvement at work (e.g. "I took on lots of projects") and social harmony (e.g. "I smiled easily"). It is based on a 5-point Likert scale ranging from 1 (never) to 5 (almost always). Because the correlations between these subscales were high (they varied from .67 to .87 across the four times of measurement), the global score of the scale was used. Greater scores indicate higher psychological wellbeing at work.

Psychological distress was measured with the Psychological Distress Manifestations at Work Scale (Gilbert et al., 2011), a 23-item scale that captures three factors: irritability/aggressivity (e.g. "I had conflicts with my colleagues"), anxiety/depression (e.g. "I felt preoccupied and uneasy") and work disengagement (e.g. "I felt disinterested in my job "). The Psychological Distress Manifestations at Work Scale is also based on a 5-point Likert scale ranging from 1 (never) to 5 
(almost always). Once again, correlations between subscales were high (from .74 to .91) so the global score of the scale was used. Greater scores indicate higher psychological distress at work.

Stress was measured using the Psychological Stress Measure (PSM-9; Lemyre \& LalandeMarkon, 2009; Lemyre \& Tessier, 1988). The respondents were asked to evaluate how often they had experienced various manifestations of stress (e.g., "I felt stressed") using a 5-point Likert scale ranging from 1 (never) to 5 (almost always). Higher scores on the PSM- 9 reflect more stress.

Burnout was assessed with the Shirom-Melamed Burnout Measure (SMBM; Sassi \& Neveu, 2010; Shirom \& Melamed, 2006), a 14-item scale that captures three factors: physical fatigue (e.g., "I felt physically fatigued"), cognitive weariness (e.g., "I was too tired to think clearly") and emotional exhaustion (e.g., "I felt I was unable to be sensitive to the needs of coworkers and customers"). The SMBM relies on a 7-point Likert scale ranging from 1 (never) to 7 (always). However, a 5-point Likert scale similar to the one used to measure psychological wellbeing and distress, as well as stress, was used in this study for the sake of uniformity.

Emotion regulation was assessed with two subscales of the Difficulties in Emotion Regulation Scale (DERS; Gratz \& Roemer, 2004; Labbé, Côté, Gosselin, \& Dagenais, 2012), lack of emotional awareness subscale (6 items) and the impulse control difficulties subscale (5 items). The DERS was developed to assess difficulties in emotion regulation. The lack of emotional awareness subscale reflects an inattention to, and lack of awareness of, emotional responses (e.g., "When I'm upset, I take time to figure out what I'm really feeling", reverse scored), while the impulse control difficulties reflects difficulties remaining in control of one's behavior when experiencing negative emotions (e.g., "When I'm upset, I have difficulty controlling my behaviors"). Higher scores for each subscale indicate greater difficulties in emotion regulation (i.e., more emotion dysregulation). Employees were asked to indicate how often the items apply to themselves, with responses ranging from 1 (almost never) to 5 (almost always).

Descriptive statistics (means and standard deviations) and Cronbach coefficients for all scales presented above were analysed across all assessment time points. As can be seen in Table 2 below, all scales showed good to excellent internal consistency.

Employees' compliance with the intervention was measured using the following question: On a scale ranging from 0 (not consistent at all) to 100 (very consistent), please rate to what extent you were consistent in the listening of your daily guided meditations. The employees in Group 1 were asked this question at t2; employees in Group 2 were asked at $\mathrm{t} 3$. 
Table 2. Cronbach coefficients, means and standard deviations for all variables across the intervention

\begin{tabular}{lccccccccc}
\hline \multirow{2}{*}{ Variables } & \multirow{2}{*}{$\boldsymbol{\alpha}$} & \multicolumn{2}{c}{$\mathbf{t 1}$} & \multicolumn{2}{c}{$\mathbf{t 2}$} & \multicolumn{2}{c}{$\mathbf{t 3}$} & \multicolumn{4}{c}{$\mathbf{t 4}$} \\
\cline { 3 - 10 } & & $\boldsymbol{M}$ & $\boldsymbol{S D}$ & $\boldsymbol{M}$ & $\boldsymbol{S D}$ & $\boldsymbol{M}$ & $\boldsymbol{S D}$ & $\boldsymbol{M}$ & $\boldsymbol{S D}$ \\
\hline Mindfulness & $.91-.94$ & 2.80 & .85 & 3.04 & .85 & 3.20 & .89 & 2.81 & .85 \\
Wellbeing & $.92-.96$ & 3.66 & .52 & 3.82 & .65 & 3.88 & .52 & 3.82 & .66 \\
Distress & $.94-.96$ & 2.15 & .67 & 1.95 & .69 & 1.86 & .56 & 1.85 & .55 \\
Stress & $.89-.94$ & 2.74 & .74 & 2.43 & .90 & 2.26 & .69 & 2.23 & .73 \\
Burnout & $.91-.95$ & 2.55 & .67 & 2.27 & .82 & 2.13 & .61 & 2.08 & .68 \\
Lack of emotional & $.75-.79$ & 3.39 & .68 & 3.50 & .65 & 3.68 & .73 & 3.68 & .73 \\
awareness & & & & & & & & & \\
Impulse control difficulties & $.81-.91$ & 2.09 & .81 & 1.93 & .78 & 1.94 & .69 & 1.76 & .51 \\
\hline
\end{tabular}

\subsection{Data analyses}

Our first three hypotheses were assessed using univariate and multivariate analysis of variance (ANOVA and MANOVA) and the prediction analysis technique (Hildebrand, Rosenthal, \& Laing, 1977; Szabat, 2005). Grégoire and Lachance (2015) have pointed out that, in studies aimed at assessing the influence of MBIs among non-clinical populations, the prediction analysis technique represents a valuable complement to commonly applied statistical techniques such as ANOVA and MANOVA. They argue that in these studies participants often show few difficulties at baseline, making it more difficult to detect improvement or changes using traditional types of analyses of variance. Moreover, others have shown that analysis of variance sometimes underestimate the effects of an intervention, especially in small sample sizes (Ducharme, Lévesque, Zarit, Lachance \& Giroux, 2007; Lévesque, Ducharme, Zarit, Lachance \& Giroux, 2008). Unlike ANOVA and MANOVA, prediction analysis takes ceiling and floor effects into account in the score distribution at baseline, and the phenomenon of regression towards the mean for participants at both ends of the scale (extreme scores) (Whitlatch, Zarit \& von Eye, 1991). Additionally, while ANOVA and MANOVA are used to analyze the mean differences between groups, prediction analysis serves to assess expected successful outcomes for those who take part in the intervention (experimental condition), and unsuccessful outcomes for those not participating in the intervention (control condition). This technique allows predictions for each participant based on: 1) their scores on dependant variables at baseline, and 2) the group they are in (experimental or control). Our fourth hypothesis was tested according to Hayes' (2013) procedure for testing mediation effects using regression-based path analysis via Mplus Version 6 (Muthén \& Muthén, 2011). This method allowed us to generate bootstrap confidence intervals for the indirect effects of mindfulness to wellbeing, distress and burnout through the mediating variables of impulse control and emotional awareness. This technique has proven to be superior to the causal steps approach devised by Baron and Kenny (1986). In fact, many simulations' studies have shown that bootstrapping is one of the most statistically powerful methods for testing mediation with the lowest Type I error, while the causal steps approach is one of the least statistically powerful approaches (Hayes, 2009).

\section{Results}

In general, employees were consistent in the listening of their daily meditation sessions. The compliance rate was high within both groups (87.8\% within Group 1 and 83\% within Group 2). No significant correlations were found between compliance scores and mindfulness, mental 
health or emotion regulation scores within groups. Therefore, this variable was not taken into account in further analyses.

According to our first hypothesis, mindfulness was expected to increase from preintervention to post-intervention and to do so in distinct ways for each group. Within Group 1, it would significantly increase between $\mathrm{t} 1$ and $\mathrm{t} 2$ and the effect would be maintained until $\mathrm{t} 4$ (or slightly drop). Within Group 2, mindfulness would significantly increase between $\mathrm{t} 2$ and $\mathrm{t} 3$ and the effect would be maintained until $t 4$ (or slightly drop). In other words, a group-by-time interaction effect was hypothesized. To test these predictions, a two-way mixed-design analysis of variance (ANOVA) with one between-subjects factor (Group 1 and Group 2) and one withinsubjects factor (time: $\mathrm{t} 1, \mathrm{t} 2, \mathrm{t} 3$ and $\mathrm{t} 4$ ) was used. Prior to running the ANOVA, the normality of the data was tested using the Kolmogorov-Smirnov and Shapiro-Wilk tests. We also tested the homogeneity of variance-covariance matrices using Box's $M$ test, while the presence of outliers was checked (.001 level) using both univariate (z-scores) and multivariate (Mahalanobis distance) approaches. The results of the ANOVA revealed no interaction effect between groups and time $[\mathrm{F}(3,39)=1.64, p=.19]$, no main effect for time $[\mathrm{F}(3,39)=1.95, p=.13]$, but a main group effect $\left[\mathrm{F}(1,39)=7.51, p=.009, \eta_{\mathrm{p}}^{2}=.16\right]$. In order to better understand how mindfulness evolved during the intervention, Bonferroni pairwise comparisons were examined even though no interaction and main effect for time emerged from the analyses. These comparisons showed that mindfulness increased between $\mathrm{t} 1$ and $\mathrm{t} 3$ (mean difference $=.44, p=0.003$ ) within both groups and did not change significantly between $\mathrm{t} 3$ and $\mathrm{t} 4$ (mean difference $=-.36, n s$ ). However, mindfulness did not increase as expected. While it did increase significantly between $\mathrm{t} 2$ and $\mathrm{t} 3$ within Group 2, it did not increase between $t 1$ and $t 2$ for Group 1 . Taken together, these results partly support the first hypothesis that employees' mindfulness would increase from preintervention to post-intervention. Table 3 below shows how mindfulness scores evolved throughout the intervention within each group.

Our second hypothesis was that mental health would increase in both groups over the course of the intervention. According to the same logic presented above, mental health would significantly increase between $\mathrm{t} 1$ and $\mathrm{t} 2$ for Group 1 and the effect would be maintained until $t 4$ (or slightly drop). For Group 2, it would significantly increase between $\mathrm{t} 2$ and $\mathrm{t} 3$ and the effect would be maintained until $\mathrm{t} 4$ (or slightly drop). The zero-order correlations between the mental health indicators used in this study (psychological well-being, psychological distress, stress and burnout) were first examined at each time of measurement. Because correlations between these indicators were high, this second hypothesis was tested with a doubly multivariate analysis of variance (MANOVA) with group (Group 1 and Group 2) as the between-subjects variable and time (t1, t $2 \mathrm{t} 3$ and $\mathrm{t} 4$ ) as the within-subject variable to control for Type I error. Assumption testing was conducted to check for normality, homogeneity of variance-covariance matrices, and univariate and multivariate outliers, with no serious violations noted. The MANOVA revealed a time-by-group interaction effect $\left[\mathrm{F}(12,28)=3.08, p=.007\right.$, Wilks' lambda $\left.=.43, \eta_{\mathrm{p}}{ }^{2}=.57\right]$, a main time effect $\left[\mathrm{F}(12,28)=2.63, p=.017\right.$, Wilks' lambda $\left.=.47, \eta_{\mathrm{p}}{ }^{2}=.53\right]$ and a main group effect $[\mathrm{F}(4$, $36)=2.98, p=.03, W_{i l k s}^{\prime}$ lambda $\left.=.75, \eta_{p}^{2}=.25\right]$. The interaction effect suggests that the combined mental health indicator evolved differently for each group over time. The examination of this effect at the univariate level showed that psychological well-being $[\mathrm{F}(3,117)=8.26, \mathrm{p}<.000$, $\left.\eta_{\mathrm{p}}{ }^{2}=.18\right]$, psychological distress $\left[\mathrm{F}(3,117)=5.90, \mathrm{p}=.001, \eta_{\mathrm{p}}{ }^{2}=.13\right]$, stress $[\mathrm{F}(3,117)=4.75$, $\left.\mathrm{p}=.004, \eta_{\mathrm{p}}{ }^{2}=.10\right]$ and burnout $\left[\mathrm{F}(3,117)=6.54, \mathrm{p}<.001, \eta_{\mathrm{p}}{ }^{2}=.14\right]$ all evolved differently for each group over time. 
Table 3. Evolution of mindfulness, mental health and emotion regulation indicators throughout the study for both groups

\begin{tabular}{|c|c|c|c|c|c|c|c|c|c|c|c|c|c|c|c|c|}
\hline \multirow{3}{*}{ Variables } & \multicolumn{8}{|c|}{$\begin{array}{c}\text { Gr. } 1 \\
(n=26)\end{array}$} & \multicolumn{8}{|c|}{$\begin{array}{c}\text { Gr. } 2 \\
(n=15)\end{array}$} \\
\hline & \multicolumn{2}{|c|}{ t1 } & \multicolumn{2}{|c|}{ t2 } & \multicolumn{2}{|c|}{ t3 } & \multicolumn{2}{|c|}{ t4 } & \multicolumn{2}{|c|}{ t1 } & \multicolumn{2}{|c|}{ t2 } & \multicolumn{2}{|c|}{ t3 } & \multicolumn{2}{|c|}{ t4 } \\
\hline & $M$ & $S D$ & $M$ & $S D$ & $M$ & $S D$ & $M$ & $S D$ & $M$ & $S D$ & $M$ & $S D$ & $M$ & $S D$ & $M$ & $S D$ \\
\hline Mindfulness & 3.03 & 0.91 & 3.22 & 0.76 & 3.42 & 0.81 & 2.76 & 0.92 & 2.49 & 0.80 & 2.59 & 0.84 & 2.98 & 0.87 & 2.91 & 0.75 \\
\hline \multicolumn{17}{|l|}{ Mental health } \\
\hline Psychological wellbeing & 3.87 & 0.47 & 4.09 & 0.41 & 3.94 & 0.54 & 3.88 & 0.63 & 3.30 & 0.44 & 3.33 & 0.76 & 3.78 & 0.53 & 3.73 & 0.59 \\
\hline Psychological distress & 1.93 & 0.55 & 1.70 & 0.47 & 1.73 & 0.50 & 1.81 & 0.61 & 2.42 & 0.74 & 2.46 & 0.80 & 2.14 & 0.64 & 1.94 & 0.46 \\
\hline Stress & 2.38 & 0.57 & 2.00 & 0.58 & 2.06 & 0.60 & 2.06 & 0.71 & 3.07 & 0.86 & 3.11 & 1.01 & 2.55 & 0.81 & 2.55 & 0.70 \\
\hline Burnout & 2.31 & 0.55 & 1.89 & 0.47 & 1.98 & 0.59 & 1.99 & 0.72 & 2.86 & 0.70 & 2.90 & 0.92 & 2.37 & 0.65 & 2.23 & 0.62 \\
\hline \multicolumn{17}{|l|}{ Emotion regulation } \\
\hline Lack of emotional awareness & 2.3 & 0.50 & 2.10 & 0.44 & 2.23 & 0.45 & 2.48 & 0.71 & 2.33 & 0.60 & 2.31 & 0.65 & 2.15 & 0.63 & 2.44 & 0.71 \\
\hline Impulse control difficulties & 1.93 & 0.51 & 1.86 & 0.69 & 1.86 & 0.65 & 1.73 & 0.51 & 2.06 & 0.94 & 2.24 & 0.97 & 2.01 & 0.75 & 1.81 & 0.52 \\
\hline
\end{tabular}


Simple effects and Bonferroni pairwise comparisons showed that within Group 1 psychological wellbeing significantly increased between $\mathrm{t} 1$ and $\mathrm{t} 2$, while psychological distress, stress and burnout decreased during that period. However, no significant differences were found on any of these indicators between $t 1$ and $t 4$, suggesting that the positive effects of the intervention did not last until follow-up for these employees. Within Group 2, psychological wellbeing significantly increased between $\mathrm{t} 2$ and $\mathrm{t} 3$ while psychological distress, stress and burnout decreased. Between t2 and $t 4$, significant differences were observed for all indicators, suggesting that the effects of the intervention lasted up to three months for these employees.

The third hypothesis stated that the intervention would help improve emotion regulation. Therefore, both lack of emotional awareness and impulse control difficulties scores were expected to decrease significantly (between $\mathrm{t} 1$ and $\mathrm{t} 2$ for Group 1 and between $\mathrm{t} 2$ and $\mathrm{t} 3$ for Group 2) and these effects would last over time (or slightly drop). This hypothesis was tested using a doubly multivariate analysis of variance (MANOVA), with group (Group 1 and Group 2) as the between-subjects variable and time ( $\mathrm{t} 1, \mathrm{t} 2 \mathrm{t} 3$ and $\mathrm{t} 4)$ as the within-subject variable after having checked for normality, homogeneity of variance-covariance matrices, and univariate and multivariate outliers. The multivariate analysis revealed a nonsignificant time-by-group interaction effect $[\mathrm{F}(6,34)=1.33, p=.26$, Wilks' lambda $=.80]$, a significant main time effect $[\mathrm{F}(6$, $34)=3.8, p=.005$, Wilks' lambda $\left.=.59, \eta_{\mathrm{p}}{ }^{2}=.40\right]$ and no significant main group effect $[\mathrm{F}(2$, $38)=.42, p=.65$, Wilks' lambda $=.97]$. When the main time effect was considered separately with univariate analyses, significant differences were found for impulse control difficulties scores only. Bonferroni pairwise comparisons showed that these scores did not decrease significantly between $\mathrm{t} 1$ and $\mathrm{t} 2$ for Group 1 and between $\mathrm{t} 2$ and $\mathrm{t} 3$ for Group 2 . However, they did significantly decrease between $t 1$ and $t 4$ in both groups. These results partly support our third hypothesis. The evolution of mental health and emotion regulation indicators throughout the intervention is presented in Figures 1 to 6 below.

Figure 1. Psychological wellbeing

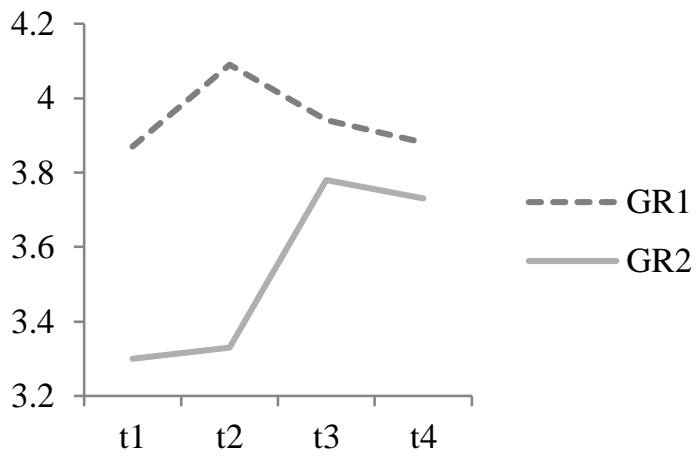

Figure 2. Psychological distress

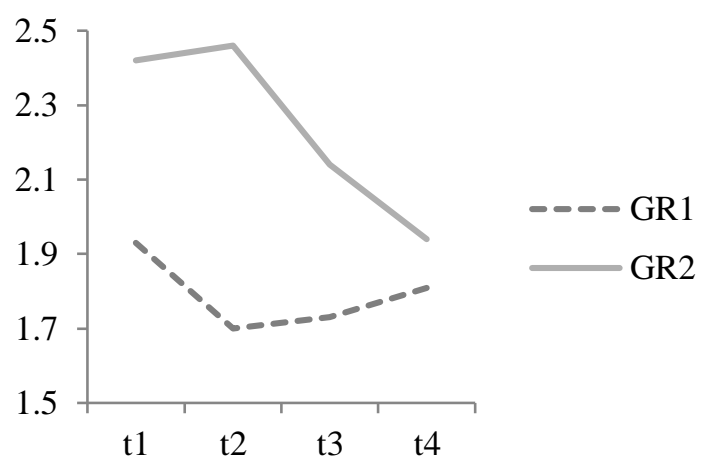


Figure 3. Stress

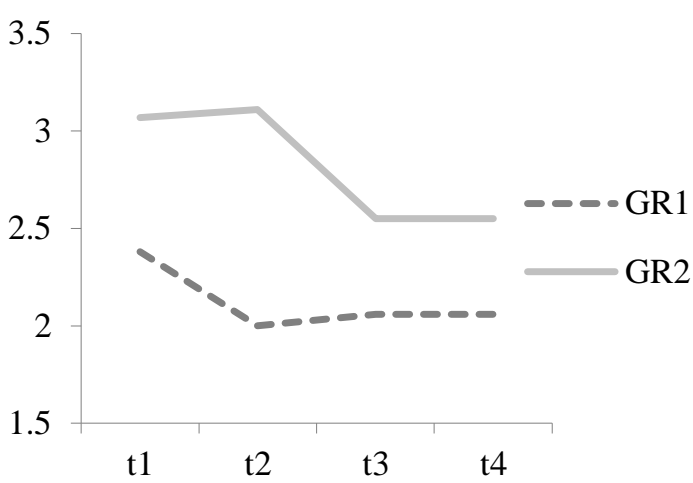

Figure 5. Emotional awareness difficulties

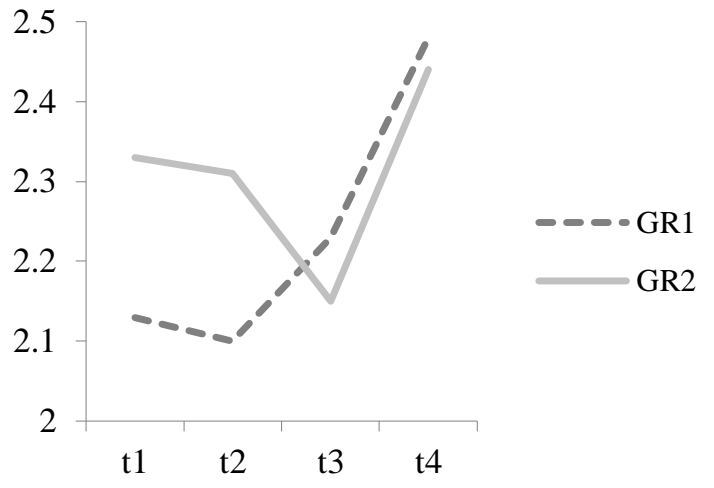

Figure 4. Burnout

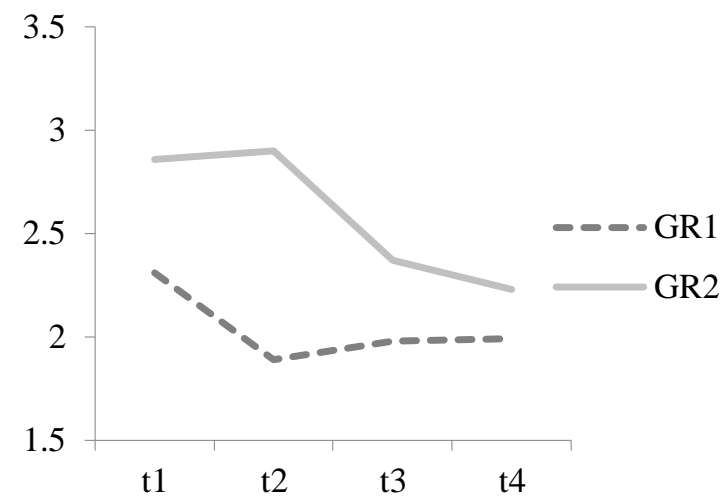

Figure 6. Impulse control difficulties

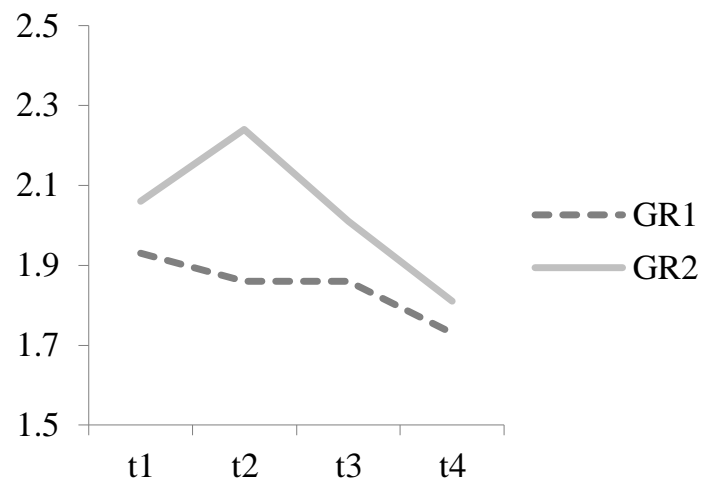

The prediction analysis technique was also used to verify our first three hypotheses and to complement the analysis of variance. In order to conduct this analysis, the participants were first divided into quartiles based on the distribution of their baseline scores for each dependent variable. For each quartile, criteria for successful and unsuccessful outcomes were defined in standard deviation units in terms of the expected change for each dependent variable. Table 4 below shows the criteria for expected successful outcomes in the experimental condition and for expected unsuccessful outcomes in the control condition based on the recommendations of Whitlatch et al. (1991).

Table 4. Predicted intervention outcomes for experimental and control conditions

\begin{tabular}{llll}
\hline $\begin{array}{l}\text { Positive } \\
\text { indicators }\end{array}$ & $\begin{array}{l}\text { Negative } \\
\text { indicators }\end{array}$ & $\begin{array}{l}\text { Experimental condition (predicted } \\
\text { and successful outcomes) }\end{array}$ & $\begin{array}{l}\text { Control condition (predicted } \\
\text { and unsuccessful outcomes) }\end{array}$ \\
\hline Low & High & $\begin{array}{l}\text { More than 1 standard deviation of } \\
\text { improvement } \\
\text { Medium- }\end{array}$ & $\begin{array}{l}\text { Less than 1 standard } \\
\text { deviation of improvement }\end{array}$ \\
$\begin{array}{l}\text { Mew } \\
\text { Medium- } \\
\text { High }\end{array}$ & $\begin{array}{l}\text { High } \\
\text { Medium- }\end{array}$ & $\begin{array}{l}\text { Low } \\
\text { improvement }\end{array}$ & $\begin{array}{l}\text { Any improvement } \\
\text { Less than } .5 \text { standard } \\
\text { deviation of improvement } \\
\text { Stability or deterioration }\end{array}$ \\
& & $\begin{array}{l}\text { Any improvement, stability or } \\
\text { slight deterioration (less than } .5 \\
\text { standard deviation) }\end{array}$ & Stability or deterioration \\
\hline
\end{tabular}


The analyses were conducted to assess changes from $\mathrm{t} 1$ to $\mathrm{t} 2$ only, because the control group used between $\mathrm{t} 2$ and $\mathrm{t} 3$ cannot be considered a classic control group, as the employees in this group had already taken part in the intervention. Under the prediction model, successful outcomes are expected for participants taking part in the intervention (Group 1) and unsuccessful outcomes for those in the control condition (Group 2). In other words, the model proposes an association between intervention and successful outcomes. The del statistic is used to test the prediction model $^{2}$ and $z$ values serve to test whether the observed values contain more cases than expected under the assumption of no association between intervention and successful outcomes.

These analyses revealed significant differences for all dependent variables, except for lack of emotional awareness (see Table 5 below). For each of these variables, more participants in Group 1 had successful outcomes (from 51.9 to $81.5 \%$, depending on the variable) than in Group 2 (from $5.6 \%$ to $33.3 \%$ ). According to the del statistic values, the proposed model described the data from $26 \%$ to $59 \%$ better than the model based on an assumption of no association. In summary, the results of the prediction analyses indicate that the intervention had positive effects on mindfulness, mental health indicators and impulse control difficulties for members of Group 1.

Table 5. Successful and unsuccessful outcomes frequencies on dependent measures by group for time changes

\begin{tabular}{|c|c|c|c|c|c|c|c|}
\hline \multirow{3}{*}{ Dependent variables } & \multicolumn{4}{|c|}{ Change from Time 1 to Time 2} & \multirow[b]{3}{*}{ del } & \multirow[b]{3}{*}{$z$} & \multirow[b]{3}{*}{$p$} \\
\hline & \multicolumn{2}{|c|}{ Successful outcome } & \multicolumn{2}{|c|}{ Unsuccessful outcome } & & & \\
\hline & Observed & Expected & Observed & Expected & & & \\
\hline \multicolumn{5}{|l|}{ Mindfulness } & 0.26 & 1.83 & .034 \\
\hline Gr. 1 & $14(.52)$ & 11.05 & $13(.48)$ & 15.95 & & & \\
\hline Gr.2 & $4(.24)$ & 6.95 & $13(.76)$ & 10.05 & & & \\
\hline \multicolumn{5}{|l|}{ Psychological wellbeing } & 0.40 & 2.89 & .002 \\
\hline Gr. 1 & $20(.74)$ & 15.60 & $7(.26)$ & 11.40 & & & \\
\hline Gr.2 & $6(.33)$ & 10.40 & $12(.67)$ & 7.60 & & & \\
\hline \multicolumn{5}{|l|}{ Psychological distress } & 0.32 & 2.28 & .011 \\
\hline Gr. 1 & $18(.67)$ & 14.40 & $9(.33)$ & 12.60 & & & \\
\hline Gr.2 & $6(.33)$ & 9.60 & $12(.67)$ & 8.40 & & & \\
\hline \multicolumn{5}{|l|}{ Stress } & 0.46 & 3.51 & .000 \\
\hline Gr. 1 & $19(.70)$ & 13.80 & $8(.30)$ & 13.20 & & & \\
\hline Gr.2 & $4(.22)$ & 9.20 & $14(.78)$ & 8.80 & & & \\
\hline \multicolumn{5}{|l|}{ Burnout } & 0.59 & 4.77 & .000 \\
\hline Gr. 1 & $22(.81)$ & 15.60 & $5(.19)$ & 11.40 & & & \\
\hline Gr.2 & $4(.22)$ & 10.40 & $14(.78)$ & 7.60 & & & \\
\hline \multicolumn{5}{|c|}{ Lack of emotional awareness } & 0.15 & 1.08 & .140 \\
\hline Gr. 1 & $12(.44)$ & 10.20 & $15(.56)$ & 16.80 & & & \\
\hline Gr.2 & $5(.28)$ & 6.80 & $13(.72)$ & 11.20 & & & \\
\hline \multicolumn{5}{|c|}{ Impulse control difficulties } & 0.42 & 3.22 & .001 \\
\hline Gr. 1 & $14(.52)$ & 9.00 & $13(.48)$ & 18.00 & & & \\
\hline Gr.2 & $1(.06)$ & 6.00 & $17(.94)$ & 12.00 & & & \\
\hline
\end{tabular}

\footnotetext{
2 Unlike chi-square analysis, prediction analysis compares expected with observed cell frequencies only for specified prediction cells rather than among all cells.
} 
According to our fourth hypothesis, the effects of the intervention on mental health would be mediated by changes in both emotional awareness and impulse control. To test this mediating hypothesis, a series of simple indirect effects models were estimated between mindfulness and each mental health indicator through impulse control and emotional awareness using regressionbased path analysis with bootstrapped confidence intervals (Hayes, 2013). Because of the nature of our pretest-posttest control group switching replication design, residualized change scores for all variables were first computed for each participant between either $\mathrm{t} 1$ and $\mathrm{t} 2$ (Group 1) or $\mathrm{t} 1$ and $\mathrm{t} 3$ (Group 2). First, the indirect effects of mindfulness on wellbeing, distress, stress and burnout were each estimated using impulse control as a mediator. The same paths were then tested using emotional awareness as a mediator. Following Hayes (2013), these indirect effects were quantified as the product of the regression coefficient estimating the mediator (i.e., impulse control or emotional awareness) from mindfulness with the regression coefficient estimating the outcome (i.e., well-being, distress, stress or burnout) from the mediating variable.

The results showed a marginally significant indirect effect of mindfulness on psychological distress, through impulse control difficulties. First, mindfulness was found to significantly negatively predict impulse control difficulties (unstandardized path coefficient $=-.41$, standardized path coefficient $=-.43, \mathrm{SE}=.17, \mathrm{p}=.01$ ). Analyses also showed that impulse control difficulties marginally positively predicted psychological distress (unstandardized path coefficient $=.24$, standardized path coefficient $=.36, \mathrm{SE}=.12, \mathrm{p}=.05)$. Next, we estimated a biascorrected bootstrap-confidence interval (CI) for the product of theses paths. The significance of the indirect effect of mindfulness on psychological distress through impulse control would be evidenced by a confidence interval that did not include zero (Preacher \& Hayes, 2008; Hayes, 2009). Using Hayes' (2013) procedure with 5,000 bootstrap samples, our analyses revealed a marginally negative indirect effect of mindfulness on distress through impulse control difficulties (point estimate $=-.10,90 \%$ percentile $C I=-.19$ to -.01 ), suggesting a trend in which the relation of mindfulness at $\mathrm{t} 1$ to psychological distress following the intervention was mediated by impulse control. All other indirect effects of mindfulness to wellbeing, distress, stress, and burnout through impulse control or emotional awareness were nonsignificant.

\section{Discussion}

The purpose of this study was to assess the effects of a brief MBI on mindfulness, mental health and emotion regulation abilities among call center employees. The intervention proved to be helpful to increase mindfulness. In fact, mindfulness significantly increased within both groups between $\mathrm{t} 1$ and $\mathrm{t} 3$. Moreover, although mindfulness scores slightly decreased after $\mathrm{t} 3$, the changes were not statistically significant, suggesting that the effects of the intervention were maintained during the three months follow-up period within both groups. However, mindfulness did not increase as expected as no interaction effect was found. This is in part because mindfulness increased between $t 1$ and $t 2$ for Group 2 despite the fact that this group was acting as control. Although less important than the one observed in Group 1, such an increase may have masked the interaction effect. It needs to be recalled that prior to the intervention, all employees took part in a one-hour session where basic information was provided on the study, but also on mindfulness and its importance at work. This session may have had a positive impact on both groups.

The intervention also helped to increase psychological wellbeing and decrease distress, stress and burnout among participating employees. These indicators changed according to what was expected in hypothesis 2 as showed by the interaction effect. These results are consistent with the recent meta-analysis done by Virgili (2013) and show that MBIs help increase mental health 
in the workplace. They are also in line with recent studies showing that brief (Klatt et al., 2009), self-help (Cavanagh et al., 2014) MBIs delivered outside training rooms (Bazarko et al., 2013; Wolever et al., 2012) represent an effective way to reduce distress in organizations. Nevertheless, the results regarding mental health need to be interpreted with caution as the effects were maintained throughout the follow-up period only within Group 2. One possible explanation for this is that the follow-up period was longer for members of Group 1 (see Table 1 above), which may in part explain why the effects were not maintained at $t 4$ within that group. Moreover, no information was gathered on the significant life events employees might have experienced during the follow-up period. It is possible that, compared to the employees of Group 2, those of Group 1 may have had to cope with more stressful situations, at work or at home. Because of these methodological aspects, we believe that additional studies are required before drawing any firm conclusion on the long-term effects of this intervention on mental health. We also believe that the intervention would benefit from including a booster session at a later date where employees would be encouraged to continue their meditation practice, as this might insure longer-term effects.

We had hypothesized that the intervention would help call center employees to manage their emotions with more clarity and less reactivity. The results partly support this hypothesis. While the intervention did reduce impulse control difficulties, it did not have any significant impact on emotional awareness as showed by the analysis of variance and the prediction analysis. Different reasons might explain this result. For instance, employees may have had more practice, support and opportunities to develop emotional control than to develop emotional awareness. In fact, the importance of giving oneself more space of mind before taking action was a recurrent theme throughout the intervention and employees were explicitly encouraged to practice this ability at work. For example, they were encouraged to breathe and take small pauses during calls with clients in order to avoid reacting impulsively. On the contrary, the emotional awareness theme was introduced only at week 4 during the audio sessions and the one-hour meeting on emotion regulation previously described. Therefore, employees may not have had sufficient time and opportunities to cultivate a mindful stance toward their emotional experiences. Another potential explanation for this finding is that emotional awareness may best be conceptualized as a stable trait rather than a skill. This might explain why no significant changes were observed on that dimension during the intervention.

Contrary to expectations, the effects of the intervention on mental health were not mediated by changes in emotional awareness. However, the analyses did show a marginally significant trend towards an indirect effect of mindfulness on psychological distress, through impulse control difficulties. In other words, the more employees were mindful after the intervention, the less they experienced impulse control difficulties, and the less they felt psychological distress. This finding supports prior research suggesting that mindfulness training helps promote impulse control (Baer et al., 2004; Feldman et al., 2010; Fetterman et al., 2010) and extends those findings to an organizational setting.

These results were not replicated for the other mental health indicators. In addition, it must be noted that this was only marginally significant $(p=0.5)$. One possible explanation is that the study may not have lasted long enough to detect a mediation effect. Another explanation could be that the sample size may have been too small, which may have decreased statistical power. However, this trend indicates that impulse control may represent a potential mechanism by which mindfulness influences psychological distress in a population of workers who face difficult emotional demands from their clients on a daily basis. Future studies should continue to investigate to what extent MBIs prove useful in helping workers cope with emotional job 
demands, using larger samples and including additional follow-up assessments to assess potential longer-term effects of practice. So far, most studies exploring the relationship between mindfulness and emotion regulation have been conducted outside the work context, using student or clinical samples, such that empirical findings may not generalize to the work context.

This study contributes to the existing literature on mindfulness in the workplace in two important ways. First, it provides further evidence for the effectiveness of an original MBI specifically designed for call center work environments. It shows that this intervention can have positive, lasting effects on mental health and that it reduces emotional reactivity among employees. More generally, it also provides support for the use of brief, self-help MBIs in the workplace that are not classroom-based. These forms of interventions can serve as a valuable complement to traditional MBIs. Some have underlined that traditional MBIs can sometimes be difficult to implement in workplaces as they are time-consuming (Zeidan, Johnson, Diamond, David, \& Goolkasian, 2010) and have to be delivered in classroom settings (Bazarko et al., 2013). Although interventions delivered in audio format certainly have drawbacks (e.g., instructors spend very little time with the participants and cannot offer much support or guidance), they also have the advantage of being shorter and accessible from various locations. Therefore, they may be especially convenient for employees who work on a busy schedule or remotely.

This study has some limitations that warrant mention. First, it was not a fully randomized controlled trial, because four employees were unfortunately not able to take part in their allocated groups. The semi-random method used to assign these employees to groups may have introduced a selection bias to the study. The sample size was small and the participants included mostly call center agents working in the service industry. It is possible that such homogeneity added strength to the intervention beyond what would occur in a more heterogeneous sample composed of employees working in more diverse industries. Moreover, attrition was high. In fact, forty-three (43\%) of employees did not complete all four questionnaires. This is a higher rate than the one obtained by Virgili (2013). Of the 19 studies included in his meta-analysis, the overall attrition rates at posttreatment ranged from $0 \%$ to $56 \%$, with a mean attrition rate of $14.6 \%$ (SD $=$ $14.1)^{3}$. Attrition was especially problematic among members of Group 2, perhaps because employees within this group had to wait for a longer time before having access to the intervention. Consequently, the sample size of the groups was uneven, which reduced the power of the statistical analysis conducted. Finally, the amount of time employees may have listened to the meditation sessions outside their regular work hours was not taken into account. It is possible that if this information had been gathered, more nuanced results may have been obtained.

In sum, the results of this study corroborates those obtained by Grégoire and Lachance (2015) and suggests that short periods of meditation done regularly in the workplace can help employees cultivate mindfulness and reduce both their psychological distress and emotional reactivity. In the future, studies could extend the results presented in this paper in various ways. For example, randomized control trials with active group controls could be put forward in order to evaluate the efficacy of brief intervention compared to existing cognitive-behavioral and relaxation techniques that have proven effective in reducing employee distress. Studies could also be conducted to explore whether or not the intervention can be valuable for employees working in environments different to call centers. Although this intervention was designed to fit call center reality, it is conceivable that it could be used in other work settings where employees have access to a computer, headsets or a quiet room. Finally, it would be interesting to track

\footnotetext{
${ }^{3}$ It needs to be underlined that most of the studies reviewed by Virgili (2013) were shorter than the one presented here and did not include follow-up measures.
} 
mindfulness changes throughout this intervention with tools different than the ones used in this study. Indeed, the MAAS has been criticized for having poor content validity and relying only on negatively worded items. Grossman (2011) argued that using items assumed to reflect the opposite of mindfulness (i.e. operating on 'automatic pilot') and reversing their scores cannot provide a valid index of mindfulness. A promising instrument might be the one developed by Höfling, Moosbrugger, Schermelleh-Engel and Heidenreich (2011). Based on confirmatory factorial analyses (CFA), the authors built an alternative version of the MAAS containing only ten items, half of them being worded positively. They argue that the use of negatively and positively worded items can reduce response sets, contribute to a better response reporting and allows mindfulness to be measured both directly and indirectly.

\section{Authors}

Simon Grégoire

Université du Québec à Montréal

gregoire.simon@uqam.ca

Lise Lachance

Université du Québec à Montréal

Geneviève Taylor

Université du Québec à Montréal

\section{Publishing Timeline}

Received 21 June 2015

Accepted 7 October 2015

Published 18 December 2015

\section{References}

Abenavoli, R. M., Jennings, P. A., Greenberg, M. T., Harris, A. R., \& Katz, D. A. (2013). The protective effects of mindfulness against burnout among educators. The Psychology of Education Review, 37(2), 57-69.

Baer, R. (2010). Assessing mindfulness and acceptance processes in clients: Illuminating the theory and practice of change (pp. v, 319). Oakland, CA, US: Context Press/New Harbinger Publications.

Baer, R. A, Smith, G. T., \& Allen, K. B. (2004). Assessment of Mindfulness by Self-Report: The Kentucky Inventory of Mindfulness Skills. Assessment, 11(3), 191-206. http://dx.doi.org/10.1177/1073191104268029

Baron, R. M., \& Kenny, D. A. (1986). The moderator-mediator variable distinction in social psychological research: Conceptual, strategic, and statistical considerations. Journal of Personality and Social Psychology, 51(6), 1173-1182. http://dx.doi.org/10.1037/0022-3514.51.6.1173

Baruch, Y., \& Holtom, B. C. (2008). Survey response rate levels and trends in organizational research. Human Relations, 61(8), 1139-1160. http://dx.doi.org/10.1177/0018726708094863

Bazarko, D., Cate, R. A., Azocar, F., \& Kreitzer, M. J. (2013). The impact of an innovative mindfulnessbased stress reduction program on the health and well-being of nurses employed in a corporate setting. Journal of Workplace Behavioral Health, 28(2), 107-133. http://dx.doi.org/10.1080/15555240.2013.779518

Bishop, S. R. (2002). What do we really know about mindfulness-based stress reduction? Psychosomatic Medicine, 64(1), 71-83. http://dx.doi.org/10.1097/00006842-200201000-00010

Bond, F. W., \& Bunce, D. (2000). Mediators of change in emotion-focused and problem-focused worksite stress management interventions. Journal of Occupational Health Psychology, 5(1), 156-163.

http://dx.doi.org/10.1037/1076-8998.5.1.156 
Brown, K. W., \& Ryan, R. M. (2003). The benefits of being present: Mindfulness and its role in psychological well-being. Journal of Personality and Social Psychology, 84(4), 822-848. http://dx.doi.org/10.1037/0022-3514.84.4.822

Cavanagh, K., Strauss, C., Forder, L., \& Jones, F. (2014). Can mindfulness and acceptance be learnt by self-help?: A systematic review and meta-analysis of mindfulness and acceptance-based self-help interventions. Clinical Psychology Review, 34(2), 118-129. http://dx.doi.org/10.1016/j.cpr.2014.01.001

Çekmecelioğlu, H. G., Günsel, A., \& Ulutaş, T. (2012). Effects of emotional intelligence on job satisfaction: An empirical study on call center employees. Procedia - Social and Behavioral Sciences, 58, 363-369. http://dx.doi.org/10.1016/j.sbspro.2012.09.1012

Chambers, R., Gullone, E., \& Allen, N. B. (2009). Mindful emotion regulation: An integrative review. Clinical Psychology Review, 29(6), 560-572. http://dx.doi.org/10.1016/j.cpr.2009.06.005

Charbotel, B., Croidieu, S., Vohito, M., Guerin, A.-C., Renaud, L., Jaussaud, J., ... Bergeret, A. (2009). Working conditions in call-centers, the impact on employee health: A transversal study. Part II. International Archives of Occupational and Environmental Health, 82(6), 747-756. http://dx.doi.org/10.1007/s00420-008-0351-z

Ciarrochi, J., Caputi, P., \& Mayer, J. D. (2003). The distinctiveness and utility of a measure of trait emotional awareness. Personality and Individual Differences, 34(8), 1477-1490. http://dx.doi.org/10.1016/S0191-8869(02)00129-0

Cohen-Katz, J. (2004). Mindfulness-based stress reduction and family systems medicine: A natural fit. Families, Systems, E Health, 22(2), 204-206. http://dx.doi.org/10.1037/1091-7527.22.2.204

Cullen, M. (2011). Mindfulness-based interventions: An emerging phenomenon. Mindfulness, 2(3), 186193. http://dx.doi.org/10.1007/s12671-011-0058-1

Dahl, J., Wilson, K. G., \& Nilsson, A. (2004). Acceptance and commitment therapy and the treatment of persons at risk for long-term disability resulting from stress and pain symptoms: A preliminary randomized trial. Behavior Therapy, 35(4), 785-801. http://dx.doi.org/10.1016/S0005-7894(04)80020-0

De Cia, J., Hansez, I., Moreau, C., Naedenoen, F., Pichault, F., Pepermans, R., \& Van Den Bossche, V. (2012). Recherche sur le bien-etre au travail dans les centres de contacts (call centers) (p. 237). http://www.emploi.belgique.be/moduleDefault.aspx?id=33116

Ducharme, F., Lévesque, L., Zarit, S. H., Lachance, L., \& Giroux, F. (2007). Changes in health outcomes among older husband caregivers: A one-year longitudinal study. The International Journal of Aging $\mathcal{E}$ Human Development, 65(1), 73-96. http://dx.doi.org/10.2190/9754-21RH-5148-8025

Erisman, S. M., \& Roemer, L. (2010). A preliminary investigation of the effects of experimentally induced mindfulness on emotional responding to film clips. Emotion, 10(1), 72-82. http://dx.doi.org/10.1037/a0017162

Escuriex, B. F., \& Labbé, E. E. (2011). Health care providers' mindfulness and treatment outcomes: A critical review of the research literature. Mindfulness, 2(4), 242-253. http://dx.doi.org/10.1007/s12671$\underline{011-0068-z}$

Feldman, G., Greeson, J., \& Senville, J. (2010). Differential effects of mindful breathing, progressive muscle relaxation, and loving-kindness meditation on decentering and negative reactions to repetitive thoughts. Behaviour Research and Therapy, 48(10), 1002-1011. http://dx.doi.org/10.1016/j.brat.2010.06.006

Fetterman, A. K., Robinson, M. D., Ode, S., \& Gordon, K. H. (2010). Neuroticism as a risk factor for Behavioral Dysregulation: A mindfulness-mediation perspective. Journal of Social and Clinical Psychology, 29(3), 301-321. http://dx.doi.org/10.1521/jscp.2010.29.3.301

Flook, L., Goldberg, S. B., Pinger, L., Bonus, K., \& Davidson, R. J. (2013). Mindfulness for teachers: A pilot study to assess effects on stress, burnout and teaching efficacy. Mind, Brain and Education: The Official Journal of the International Mind, Brain, and Education Society, 7(3), 182-195. http://dx.doi.org/10.1111/mbe.12026

Franco, C., Mañas, I., Cangas, A. J., Moreno, E., \& Gallego, J. (2010). Reducing teachers' psychological distress through a mindfulness training program. The Spanish Journal of Psychology, 13(2), $655-666$. http://dx.doi.org/10.1017/S1138741600002328 
Friese, M., Messner, C., \& Schaffner, Y. (2012). Mindfulness meditation counteracts self-control depletion. Consciousness and Cognition, 21(2), 1016-1022. http://dx.doi.org/10.1016/j.concog.2012.01.008

Galantino, M. L., Baime, M., Maguire, M., Szapary, P. O., \& Farrar, J. T. (2005). Association of psychological and physiological measures of stress in health-care professionals during an 8-week mindfulness meditation program: Mindfulness in practice. Stress and Health, 21(4), 255-261. http://dx.doi.org/10.1002/smi.1062

Geary, C., \& Rosenthal, S. L. (2011). Sustained impact of MBSR on stress, well-being, and daily spiritual experiences for 1 year in academic health care employees. The Journal of Aleternative and Complementary Medicine, 17(10), 939-944. http://dx.doi.org/10.1089/acm.2010.0335

Gilbert, M. H., Dagenais-Desmarais, V., \& Savoie, A. (2011). Validation d'une mesure de santé psychologique au travail. European Review of Applied Psychology, 61(4), 195-203. http://dx.doi.org/10.1016/j.erap.2011.09.001

Glomb, T. M., Duffy, M. K., Bono, J. E., \& Yang, T. (2011). Mindfulness at work. In A. Joshi, H. Liao, \& J. J. Martocchio (Eds). Research in Personnel and Human Resources Management, (Vol. 30, pp. 115-157). Emerald Group Publishing Limited. http://dx.doi.org/10.1108/S0742-7301(2011)0000030005

Gold, E., Smith, A., Hopper, L., Herne, D., Tansey, G., \& Hulland, C. (2010). Mindfulness-Based Stress Reduction (MBSR) for primary school teachers. Journal of Child and Family Studies, 19(2), 184-189. http://dx.doi.org/10.1007/s10826-009-9344-0

Goodman, M. J., \& Schorling, J. B. (2012). A mindfulness course decreases burnout and improves wellbeing among healthcare providers. International Journal of Psychiatry in Medicine, 43(2), 119-128.

Goyal, M., Singh, S., Sibinga, E. M. S., Gould, N. F., Rowland-Seymour, A., Sharma, R., ... Haythornthwaite, J. A. (2014). Meditation programs for psychological stress and well-being: A systematic review and meta-analysis. JAMA Internal Medicine, 174 (3), 357-368. http://dx.doi.org/10.1001/jamainternmed.2013.13018

Grandey, A. A. (2000). Emotional regulation in the workplace: A new way to conceptualize emotional labor. Journal of Occupational Health Psychology, 5(1), 95-110. http://dx.doi.org/10.1037/1076-8998.5.1.95

Gratz, K., \& Roemer, L. (2004). Multidimensional assessment of emotion regulation and dysregulation: Development, factor structure, and initial validation of the Difficulties in Emotion Regulation Scale. Journal of Psychopathology and Behavioral Assessment, 26(1), 41-54. http://dx.doi.org/10.1023/B:JOBA.0000007455.08539.94

Grebner, S., Semmer, N., Faso, L. L., Gut, S., Kälin, W., \& Elfering, A. (2003). Working conditions, wellbeing, and job-related attitudes among call centre agents. European Journal of Work and Organizational Psychology, 12(4), 341-365. http://dx.doi.org/10.1080/13594320344000192

Grégoire, S., \& Lachance, L. (2015). Evaluation of a brief mindfulness-based intervention to reduce psychological distress at work. Mindfulness, 6(4), 836-847. http://dx.doi.org/10.1007/s12671-014-0328$\underline{9}$

Gross, J. J. (1998). The emerging field of emotion regulation: An integrative review. Review of General Psychology, 2(3), 271-299. http://dx.doi.org/10.1037/1089-2680.2.3.271

Grossman, P. (2011). Defining mindfulness by how poorly I think I pay attention during everyday awareness and other intractable problems for psychology's (re)invention of mindfulness: Comment on Brown et al. (2011). Psychological Assessment, 23(4), 1034-1040. http://dx.doi.org/10.1037/a0022713

Hassard, J., Cox, T., Murawski, S., \& DeMeyer, S. (2011). Mental health promotion in the workplace - A good practice report. Safety And Health (p. 41). https://osha.europa.eu/en/publications/reports/mentalhealth-promotion-workplace_TEWE11004ENN/view

Hayes, A. F. (2009). Beyond Baron and Kenny: Statistical mediation analysis in the new millennium. Communication Monographs, 76(4), 408-420. http://dx.doi.org/10.1080/03637750903310360

Hayes, A. F. (2013). Introduction to mediation, moderation, and Conditional Process Analysis: A regression-based approach. New York: The Guilford Press.

Hayes, S. C., Bissett, R., Roget, N., Padilla, M., Kohlenberg, B. S., Fisher, G., .. Niccolls, R. (2004). The impact of acceptance and commitment training and multicultural training on the stigmatizing attitudes and professional burnout of substance abuse counselors. Behavior Therapy, 35(4), 821-835. http://dx.doi.org/10.1016/S0005-7894(04)80022-4 
Hayes, S. C., Strosahl, K. D., \& Wilson, K. G. (1999). Acceptance and Commitment Therapy. An experimential approach to behavior change. New York: The Guilford Press.

Hayes, S. C., Strosahl, K. D., \& Wilson, K. G. (2011). Acceptance and commitment therapy, second edition: The process and practice of mindful change [Hardcover] (p. 402). New York: The Guilford Press.

Hildebrand, D. K., Rosenthal, H., \& Laing, J. D. (1977). Prediction analysis of cross classifications. New York: John Wiley \& Sons.

Hill, C. L. M., \& Updegraff, J. A. (2012). Mindfulness and its relationship to emotional regulation. Emotion, 12(1), 81-90. http://dx.doi.org/10.1037/a0026355

Höfling, V., Moosbrugger, H., Schermelleh-Engel, K., \& Heidenreich, T. (2011). Mindfulness or mindlessness?: A modified version of the Mindful Attention and Awareness Scale (MAAS). European Journal of Psychological Assessment, 27(1), 59-64. http://dx.doi.org/10.1027/1015-5759/a000045

Hülsheger, U. R., Alberts, H. J. E. M., Feinholdt, A., \& Lang, J. W. B. (2013). Benefits of mindfulness at work: The role of mindfulness in emotion regulation, emotional exhaustion, and job satisfaction. Journal of Applied Psychology, 98(2), 310-325. http://dx.doi.org/10.1037/a0031313

Irving, J. A., Dobkin, P. L., \& Park, J. (2009). Cultivating mindfulness in health care professionals: A review of empirical studies of mindfulness-based stress reduction (MBSR). Complementary Therapies in Clinical Practice, 15(2), 61-66. http://dx.doi.org/10.1016/j.ctcp.2009.01.002

Ismail, H. A. K., Coetzee, N., Du Toit, P., Rudolph, E., \& Joubert, Y. (2013). Toward gaining a competitive advantage: the relationship between burnout, job satisfaction, social support and mindfulness. Journal of Contemporary Management, 12, 448-464.

Jermann, F., Billieux, J., Larøi, F., d'Agembeau, A., Bondolfi, G., Zermatten, A., \& Van der Linden, M. (2009). Mindful Attention Awareness Scale (MAAS): Psychometric properties of the French translation and exploration of its relations with emotion regulation strategies. Psychological Assessment, 21(4), 506-514. http://dx.doi.org/10.1037/a0017032

Kabat-Zinn, J. (1990). Full catastrophe living: Using the wisdom of your mind and body to face stress, pain, and illness. New York: Delacorte.

Kabat-Zinn, J (1994). Wherever you go, there you are: Mindfulness meditation in everyday life. New York: Hyperion

Keng, S.-L., Smoski, M. J., \& Robins, C. J. (2011). Effects of mindfulness on psychological health: A review of empirical studies. Clinical Psychology Review, 31(6), 1041-1056.

http://dx.doi.org/10.1016/j.cpr.2011.04.006

Klatt, M. D., Buckworth, J., \& Malarkey, W. B. (2009). Effects of low-dose Mindfulness-Based Stress Reduction (MBSR-ld) on working adults. Health Education E Behavior, 36(3), 601-614. http://dx.doi.org/10.1177/1090198108317627

Krasner, M. S., Epstein, R. M., Beckman, H., Suchman, A. L., Chapman, B., Mooney, C. J., \& Quill, T. E. (2009). Association of an educational program in mindful communication with burnout, empathy, and attitudes among primary care physicians. JAMA: The Journal of the American Medical Association, 302(12), 1284-1293. http://dx.doi.org/10.1001/jama.2009.1384

Labbé T. P., Côté, G., Gosselin, P., \& Dagenais, I. (2012). Évaluation des difficultés de régulation émotionnelle : adaptation et validation francophone du Difficulties in Emotion Regulation Scale (DERS). In Société Québécoise de Recherche en Psychologie.

Lazarus, R., \& Folkman, S. (1984). Stress, appraisal and coping. New York: Springer.

Lemyre, L., \& Lalande-Markon, M.-P. (2009). Psychological stress measure (PSM-9): Integration of an evidence-based approach to assessment, monitoring, and evaluation of stress in physical therapy practice. Physiotherapy Theory and Practice, 25(5-6), 453-462. http://dx.doi.org/10.1080/09593980902886321

Lemyre, L., \& Tessier, R. (1988). Mesure de stress psychologique (MSP): Se sentir stressé-e. Revue Canadienne Des Sciences Du Comportement, 20(3), 302-321. http://dx.doi.org/10.1037/h0079945

Lévesque, L., Ducharme, F., Zarit, S. H., Lachance, L., \& Giroux, F. (2008). Predicting longitudinal patterns of psychological distress in older husband caregivers: Further analysis of existing data. Aging $\mathcal{E}$ Mental Health, 12(3), 333-342. http://dx.doi.org/10.1080/13607860801933414 
Mackenzie, C. S., Poulin, P. A., \& Seidman-Carlson, R. (2006). A brief mindfulness-based stress reduction intervention for nurses and nurse aides. Applied Nursing Research, 19(2), 105-109. http://dx.doi.org/10.1016/j.apnr.2005.08.002

Malarkey, W. B., Jarjoura, D., \& Klatt, M. (2013). Workplace based mindfulness practice and inflammation: A randomized trial. Brain, Behavior, and Immunity, 27, 145-154. http://dx.doi.org/10.1016/j.bbi.2012.10.009

Martín, A. A., Rodríguez, T. R., Pujol-Ribera, E., Berenguera, A., \& Moix Queraltó, J. (2013). Effectiveness of a mindfulness program in primary care professionals. Gaceta Sanitaria, 27(6), 521-528. http://dx.doi.org/10.1016/j.gaceta.2013.04.007

Masicampo, E. J., \& Baumeister, R. F. (2007). Relating mindfulness and self-regulatory processes. Psychological Inquiry, 18(4), 255-258. http://dx.doi.org/10.1080/10478400701598363

Massé, R., Poulin, C., Dassa, C., Lambert, J., Bélair, S., \& Battaglini, A. (1998). The structure of mental health: Higher-order confirmatory factor analyses of psychological distress and well-being measures. Social Indicators Research, 45(1), 475-504. http://dx.doi.org/10.1023/A:1006992032387

Muraven, M., \& Baumeister, R. F. (2000). Self-regulation and depletion of limited resources: Does selfcontrol resemble a muscle? Psychological Bulletin, 126(2), 247-259. http://dx.doi.org/10.1037/00332909.126.2.247

Muthén, L. K., \& Muthén, B. O. (2011). Mplus user's guide. (Sixth edition.). Los Angeles, CA: Muthén \& Muthén.

Nel, H., \& De Villiers, W. S. (2004). The relationship between emotional intelligence and job performance in a call centre environment. SA Journal of Industrial Pschology, 30(3), 75-81. http://dx.doi.org/10.4102/sajip.v30i3.159

Pipe, T. B., Bortz, J. J., Dueck, A., Pendergast, D., Buchda, V., \& Summers, J. (2009). Nurse leader mindfulness meditation program for stress management: A randomized controlled trial. The Journal of Nursing Administration, 39(3), 130-137. http://dx.doi.org/10.1097/NNA.0b013e31819894a0

Preacher, K. J., \& Hayes, A. F. (2008). Asymptotic and resampling strategies for assessing and comparing indirect effects in multiple mediator models. Behavior Research Methods, 40(3), 879-891. http://dx.doi.org/10.3758/BRM.40.3.879

Reb, J., Narayanan, J., \& Ho, Z. W. (2013). Mindfulness at work: Antecedents and consequences of employee awareness and absent-mindedness. Mindfulness, 6(1), 111-122. http://dx.doi.org/10.1007/s12671-013-0236-4

Roeser, R. W., Schonert-Reichl, K. A., Jha, A., Cullen, M., Wallace, L., Wilensky, R., ... Harrison, J. (2013). Mindfulness training and reductions in teacher stress and burnout: Results from two randomized, waitlist-control field trials. Journal of Educational Psychology, 105(3), 787-804. http://dx.doi.org/10.1037/a0032093

Roeser, R. W., Skinner, E., Beers, J., \& Jennings, P. A. (2012). Mindfulness training and teachers' professional development: An emerging area of research and practice. Child Development Perspectives, 6(2), 167-173. http://dx.doi.org/10.1111/j.1750-8606.2012.00238.x

Ruths, F. A., Zoysa, N., Frearson, S. J., Hutton, J., Williams, J. M. G., \& Walsh, J. (2013). Mindfulnessbased cognitive therapy for mental health professionals-a pilot study. Mindfulness, 4(4), $289-295$. http://dx.doi.org/10.1007/s12671-012-0127-0

Sassi, N., \& Neveu, J. -P. (2010). Traduction et validation d'une nouvelle mesure d'épuisement professionnel: Le Shirom-Melamed Burnout Measure. Canadian Journal of Behavioural Science, 42(3), 177-184. http://dx.doi.org/10.1037/a0017700

Segal, Z. V, Williams, J. M. G., \& Teasdale, J. D. (2002). Mindfulness-Based Cognitive Therapy for depression. A new approach to preventing relapse. New York: The Guilford Press.

Shamsuddin, N., \& Rahman, R. A. (2014). The relationship between emotional intelligence and job performance of call centre agents. Procedia - Social and Behavioral Sciences, 129, 75-81. http://dx.doi.org/10.1016/j.sbspro.2014.03.650

Shapiro, S. L., Astin, J. A., Bishop, S. R., \& Cordova, M. (2005). Mindfulness-based stress reduction for health care professionals: Results from a randomized trial. International Journal of Stress Management, 12(2), 164-176. http://dx.doi.org/10.1037/1072-5245.12.2.164 
Shapiro, S. L., Carlson, L. E., Astin, J. A., \& Freedman, B. (2006). Mechanisms of mindfulness. Journal of Clinical Psychology, 62(3), 373-386. http://dx.doi.org/10.1002/jclp.20237

Shirom, A. (1989). Burnout in work organizations. In C. L. Cooper, \& I. Robertson (Eds.), International review of industrial and organization psychology (pp. 25-48). Chichester, U.K.: Wiley.

Shirom, A., \& Melamed, S. (2006). A comparison of the construct validity of two burnout measures in two groups of professionals. International Journal of Stress Management, 13(2), 176-200. http://dx.doi.org/10.1037/1072-5245.13.2.176

Szabat, K. A. (2005). Prediction analysis of cross-classifications. In B. S. Everitt \& D. C. Howell (Eds.), Encyclopedia of statistics in behavioral science (Vol. 3, pp. 1573-1579). Chichester: Wiley. http://dx.doi.org/10.1002/0470013192.bsa499

Teper, R., Segal, Z. V., \& Inzlicht, M. (2013). Inside the mindful mind: How mindfulness enhances emotion regulation through improvements in executive control. Current Directions in Psychological Science, 22(6), 449-454. http://dx.doi.org/10.1177/0963721413495869

The Shepell-fgi Research Group. (2008). Employee health and well being: Trends in the call centre sector. https://www.workplacestrategiesformentalhealth.com/pdf/Call Centre Workers TrendsintheCallCe ntreSector_Resource.pdf

Trochim, W., \& Donnelly, J. P. (2007). The Research Methods Knowledge Base (3rd ed.). Mason, OH: Atomic Dog.

Virgili, M. (2013). Mindfulness-based interventions reduce psychological distress in working adults: a meta-analysis of intervention studies. Mindfulness, 6(2), 326-337. http://dx.doi.org/10.1007/s12671$\underline{013-0264-0}$

Walach, H., Nord, E., Zier, C., Dietz-Waschkowski, B., Kersig, S., \& Schüpbach, H. (2007). Mindfulnessbased stress reduction as a method for personnel development: A pilot evaluation. International Journal of Stress Management, 14(2), 188-198. http://dx.doi.org/10.1037/1072-5245.14.2.188

Whitlatch, C. J., Zarit, S. H., von Eye, A. (1991). Efficacy of interventions with caregivers: A reanalysis. Gerontoligist, 31(1), 9-14. http://dx.doi.org/10.1093/geront/31.1.9

Wolever, R. Q., Bobinet, K. J., McCabe, K., Mackenzie, E. R., Fekete, E., Kusnick, C. A., \& Baime, M. (2012). Effective and viable mind-body stress reduction in the workplace: A randomized controlled trial. Journal of Occupational Health Psychology, 17(2), 246-258. http://dx.doi.org/10.1037/a0027278

Zeidan, F., Johnson, S. K., Diamond, B. J., David, Z., \& Goolkasian, P. (2010). Mindfulness meditation improves cognition: Evidence of brief mental training. Consciousness and Cognition, 19(2), 597-605. http://dx.doi.org/10.1016/j.concog.2010.03.014 